\title{
Comparative Analysis of Simple Additive Weighting Method and Weighted Product Method to New Employee Recruitment Decision Support System (DSS) at PT. Warta Media Nusantara
}

\author{
Agus Setyawan ${ }^{1}$, Florentina Yuni Arini' ${ }^{2}$, Isa Akhlis ${ }^{3}$ \\ ${ }^{1,2,3}$ Computer Science Major, Mathematics and Science Faculty, Universitas Negeri Semarang \\ Email: ${ }^{1}$ agus_st@students.unnes.ac.id, ${ }^{2}$ floyuna@mail.unnes.ac.id, ${ }^{3}$ isa.akhlis@mail.unnes.ac.id
}

\begin{abstract}
Issue handling of inadvertence situations in the decision-making process of recruiting new employees at PT. Warta Media Nusantara that use criteria value of interviews, field test, a psychological test and medical check-up requires Multi Attribute Decision Making (MADM) as an auxiliary method of decision-making on the prospective eligible employee to be accepted in the company. There are various MADM methods, such as Simple Additive Weighting (SAW) method and Weighted Product (WP) method. Both of these methods are known as the most common method used in handling MADM issues, so in this study both methods are applied to the DSS and analyzed the differences in terms of obtained results and the execution time required for each method. The results of the study of the application of SAW and WP methods in the recruitment of new employees DSS there are some differences in the results of the candidates rank order and the differences in execution time of each method. The differences in rank order of these methods are due to the effects of alternative values, weighting criteria, and the calculation method. WP method is able to provide more rigorous result than SAW method, while the difference in execution time of SAW and WP methods explains that the execution time of SAW method relatively quick because SAW calculation method has a simpler process than the process of WP calculation methods.
\end{abstract}

Keywords: Simple Additive Weighting, Weighted Product, Decision Support System

\section{INTRODUCTION}

The issue of decision-making can be found in various fields, one of which is in terms of recruiting new employees. Recruitment is a series of events that began when an enterprise or organization requires labour and hiring to obtain the qualified candidates in accordance with the position or positions available [1]. Recruitment of new employees at PT. Warta Media Nusantara is done by giving a value to the candidate alternative for some predefined criteria. The criteria given are Interview, Field Test, Psychological Test, and Medical Chek-up. Each of these criteria has a value of its own weight. In PT. Warta Media Nusantara there are some issues in the process of recruiting new employees. The issues include delays in decision-making and decisionmaking inaccuracies caused by inadvertence of the decision makers. To solve these problems, it is required a decision-making model that can be used as reference for the decision makers so that the decision will be more accurate.

Multi-attribute Decision Making is a model used to find the optimal alternative of a number of alternatives to the established criteria. The basis of MADM is determining 
the weight value for each attribute, followed by the ranking process that will select the alternative which has been given [2]. There are various kinds of methods in the MADM model, such as Simple Additive weighting (SAW) method and Weighted Product (WP) method. Both methods are said to be the most frequently used method in the completion of MADM issues, necessitating a comparative analysis to determine the characteristics of both methods.

The application of SAW and WP method in decision support systems, considered being able to answer the issues of recruiting new employees at PT. Warta Media Nusantara. DSS itself can be defined as utilization of computer as a media for decision-making used to assist the decision makers so that decisions can be made in a relatively short time [3]. A comparative analysis for the results and the execution time of both methods in New Employees Recruitment DSS can indicate the characteristic features of each method, it is as described in the study [4] which states that each method of MADM have different characteristics calculation. In the study [5] it is also mentioned that each method has its own advantages and disadvantages. In the study [6] also explained that the SAW method is a method that quite popular for MADM problem solving, while in the study [7] explains that WP method is a method that can solve multi-dimensional problems, so that in this case comparative analysis of the two methods is necessary to find out the advantages and disadvantages of each method in terms of given outcome and execution time required in decision-making.

Simple Additive Weighting method is a weighted summation method, however prior to the performance value summation of each alternative on all attributes, this method will first execute the normalization process of decision matrix $(\mathrm{X})$ to a scale that can be compared with all the ratings of existing alternatives [2]. The equation used to find the normalization value is as follows:

$$
r_{i j}=\left\{\begin{array}{l}
\frac{x_{i j}}{\max _{i} x_{i j}}, \text { if } j \text { is benefit attribute } \\
\frac{\min _{i} x_{1 j} j}{x_{i j}}, \text { if } j \text { is cost attribute }
\end{array}\right.
$$

where $x_{i j}$ is the criterion values of each alternative, $\max _{i} x_{i j}$ is the largest alternative value to an attribute, and $\min _{\mathrm{i}} x_{\mathrm{i} i}$ is the smallest alternative value of an attribute. As for calculating the final preference value uses the following equation:

$$
V_{\mathrm{i}}=\sum_{j=1}^{n} W_{j} x_{i j}
$$

where $W_{\mathrm{i}}$ is the weight value of each attribute, and $r_{\mathrm{ij}}$ is a normalized value of alternative performance rating.

Weighted Product method is a method that uses multiplication to connect rating attributes, where each attribute rating should be raised first to a pertinent weight attribute [2]. But first, it's required to improve weight value $\Sigma W_{i}=1$ by dividing the weight value to the summation of all the weights before the process of calculating vector $\mathrm{S}$ value. The equation used to find the value of vector $\mathrm{S}$ is as follows:

$$
S_{i}=\prod_{j=1}^{n} X_{i j}{ }^{W_{j}} ; \text { with } \mathrm{i}=1,2, \ldots, \mathrm{m}
$$


Whereas to find the value of vector V's final preference used the following equation:

$$
V_{i}=\frac{\prod_{j=1}^{n} x_{i j}{ }^{W_{j}}}{\prod_{j=1}^{n}\left(x_{j}^{*}\right)^{W_{j}}} \text {; with } \mathrm{i}=1,2, \ldots, \mathrm{m}
$$

\section{METHODS}

Preliminary studies conducted to determine the general picture regarding the case of new employee recruitment, which is related to a system that runs in the process of hiring new employees as well as issues encountered in the recruitment process. The data collection is done by literary study related to SAW and WP methods as literature source. Afterwards, through interviews and observations, new candidates' related alternative data obtained, the data criteria used in the recruitment of new employees, and value data obtained by each new candidate alternative on each specified criteria.

Waterfall selected as the method used in the development of the new employees recruitment system. The steps of the Waterfall method include requirement analysis, design, coding, and testing [8]. Requirement analysis shows an overview of the needs of functionalist system and the needs of non-functionalist system. Functionalist needs related to systems must be able to input, process, and provide output. While nonfunctionalist needs related to system devices used in system development. In the design phase, the system design is done in the form of a flowchart, Entity Relationship Diagram (ERD), Data Flow Diagram (DFD), database schema and table structure. Figure 1 below shows the flowchart of SAW and WP methods on the new employee recruitment DSS.

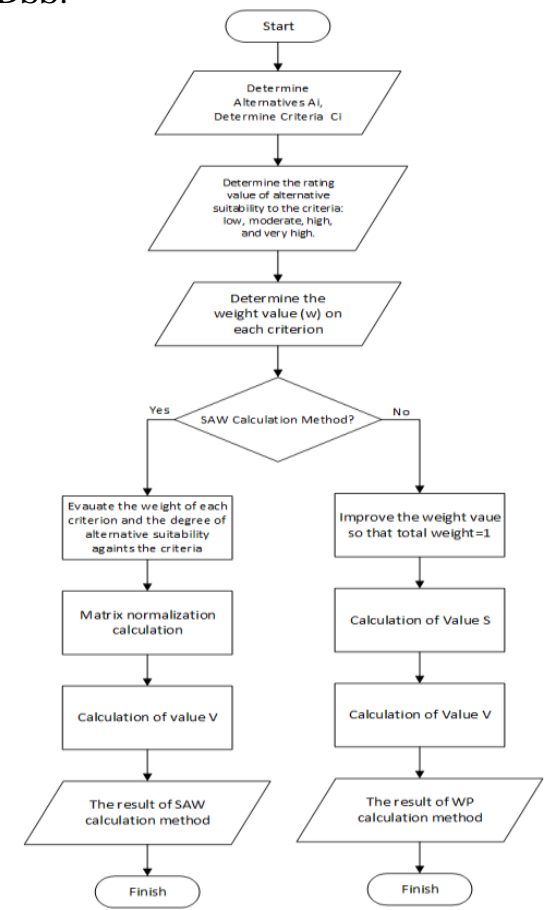

Figure 1. New Employee Recruitment DSS Flowchart 
Figure 1 described related process flow of each method in the New Employee Recruitment DSS. The implementation process of each method, starting with determining $a_{\mathrm{i}}$ alternatives and $\mathrm{c}_{\mathrm{i}}$ criteria followed by determining the rating value of suitability alternative to a criteria up to determine the weight of each criterion. Furthermore is the calculation process for each method. SAW method normalize values in advance until the final calculation of preference value, while the WP method using weights improvement prior on the calculation of the $S$ vector up to the calculation of the $\mathrm{V}$ vector. Then to find the ERD of new employee recruitment DSS, where the Entity Relationship Diagram (ERD) is a calculation model using the arrangement of data stored in the system abstractly [9], the ERD of New Employee Recruitment DSS can be seen in Figure 2.

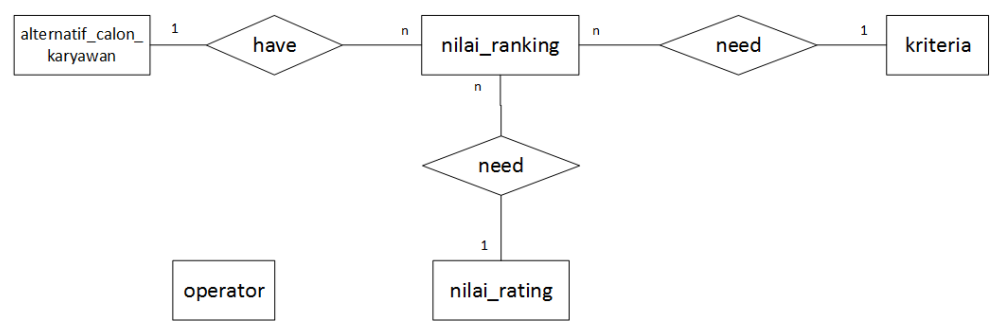

Figure 2. ERD of New Employee Recruitment DSS

Figure 2 explains the relation of each entity on the New Employee Recruitment DSS such as alternative entities of candidates who has ranking score or alternative performance value on each criterion with a value rating that has been determined. Then in the following Figure 3, described related data flow from DFD New Employee Recruitment DSS.

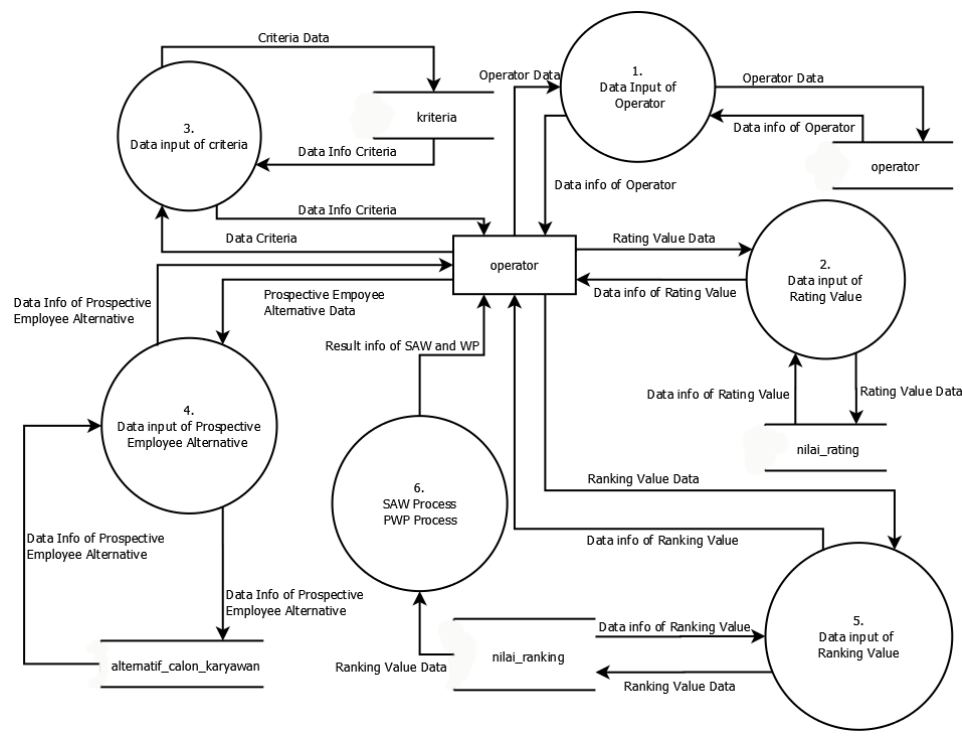

Figure 3. DFD of New Employee Recruitment DSS 
Based on Figure 3 there are six process related to the data flow on the New Employee Recruitment DSS. The process is the operator data input that is the process of managing New Employee Recruitment DSS user operator, furthermore there is a process of rating value data input that is process related to rating value of alternative compatibility against the criteria, and the next is a process of criteria data input, alternatives data input, and the value rankings data input or the alternative performance rating value, so that finally can be done the calculation of SAW and WP methods.

Furthermore in the coding phase, conversion design that has been made at the design stage into New Employee Recruitment DSS using PHP as a programming language and MySQL as the database is performed. After the coding is completed, the testing phase is required to determine the suitability of the created system against the planned system.

\section{RESULT AND DISCUSSION}

\subsection{The Implementation of SAW and WP Methods}

The implementation of SAW and WP methods on the New Employee Recruitment DSS at PT. Warta Media Nusantara using 55 alternate data of the prospective employees at Advertising Admin field. The 55th data is entered into the calculation of each method in the DSS. The calculation process also requires the weight of each criterion specified in the new employee recruitment. The following Table 1 shows a list of criteria along with the types and weight values used in SAW and WP calculation methods.

Table 1. Criteria for New Employee Recruitment

\begin{tabular}{llcc}
\hline No & Criteria Name $\left(\mathrm{C}_{2}\right)$ & Criteria Type & Criteria Weights \\
\hline 1 & Interview $\left(\mathrm{C}_{2}\right)$ & Benefit & 1 \\
2 & Field Test $\left(C_{2}\right)$ & Benefit & 2 \\
3 & Psychological Test $\left(C_{2}\right)$ & Benefit & 3 \\
4 & Medical Chek-up $\left(\mathrm{C}_{4}\right)$ & Benefit & 4 \\
\hline
\end{tabular}

Performance rating scoring for each alternative potential employee at each criterion in Table 1 is shown in Table 2 below.

Table 2. Suitability Rating Value

\begin{tabular}{llc}
\hline No & Match Rating & Value Rating \\
\hline 1 & Very High (HV) & 4 \\
2 & High (H) & 3 \\
3 & Moderate (M) & 2 \\
4 & Low (L) & 1 \\
\hline
\end{tabular}

In the SAW calculation, performance rating value of each prospective employee alternative for each criterion first normalized using equation (1). After the normalized performance rating value is obtained, SAW method conduct a final preference value using equation (2). 
Whereas the WP calculation method executes improvement of criteria weight in advance before the process of seeking the final value of WP method preferences. Once the improvement weight value of each criterion is acquired, the search process is carried out to find out $S$ vector value for each prospective employees alternative using equation (3). Based on the of $S$ vector value that has been obtained, the calculation method is carried out to determine the final preference value of WP method using equation (4) in order to obtain the preferences' final value of WP method for each alternative.

In Table 3 below is shown the alternative data of candidates who are accepted as New Employees at PT. Warta Media Nusantara along with the SAW preference value, SAW rank, WP preference value and WP rank.

Table 3. Results of The Final Preference Value of Accepted Employees

\begin{tabular}{|c|c|c|c|c|c|}
\hline No & Employee Name (Alternativef/A $\left.A_{i}\right)$ & SAW Value & SAW Rank & WP Value & WP Rank \\
\hline 1 & Aditya Ganang Pratama $\left(A_{27}\right)$ & 9.5 & 1 & 0.02789 & 1 \\
\hline 2 & Ari Kosyati $\left(A_{4 s}\right)$ & 8.25 & 8 & 0.02444 & 8 \\
\hline 3 & Dhika Mahendrayana $\left(A_{z}\right)$ & 8.5 & 6 & 0.02515 & 4 \\
\hline 4 & Dimas Setyo Humono $\left(A_{z z}\right)$ & 9.25 & 3 & 0.02742 & 2 \\
\hline 5 & Ekky Mardianasari $\left(A_{s s}\right)$ & 9 & 4 & 0.02633 & 3 \\
\hline 6 & Herdito Daru Wjanarko $\left(A_{2}\right)$ & 9.25 & 2 & 0.02602 & 4 \\
\hline 7 & Lisna Puji Wijayanti $\left(A_{41}\right)$ & 8.75 & 5 & 0.02588 & 5 \\
\hline 8 & Odhik Dermawan Surya Saputra $\left(A_{\mathbb{S}}\right)$ & 8.5 & 7 & 0.02515 & 7 \\
\hline 9 & Rosita Adi Lestari $\left(A_{27}\right)$ & 7.75 & 10 & 0.02307 & 10 \\
\hline 10 & Suci Widyawati $\left(A_{s z}\right)$ & 8 & 9 & 0.02319 & 9 \\
\hline
\end{tabular}

\subsection{Comparative Analysis of SAW and WP Methods}

Based on Table 3, there are some differences in the alternative rank order of the candidates. The difference lies in the $2^{\text {nd }}$ and $4^{\text {th }}$ rank order of each method. In profound, the results of SAW and WP calculation method are shown in Figure 1 and Figure 2.

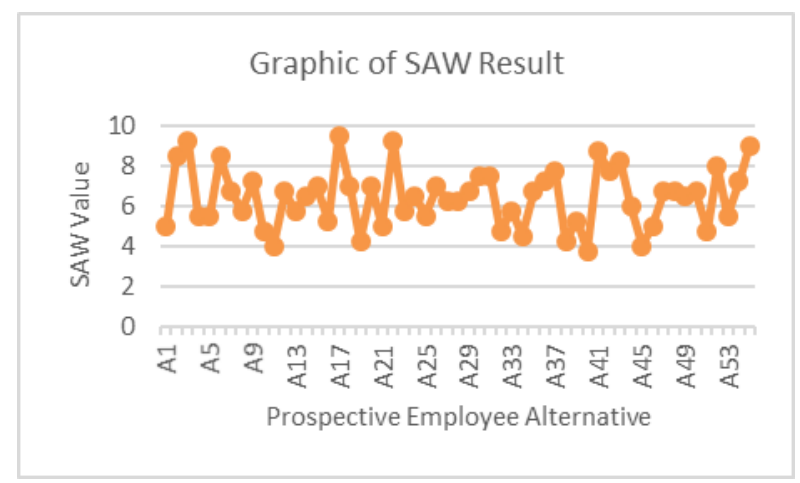

Figure 1. Graphic of The SAW Calculation Method Result 


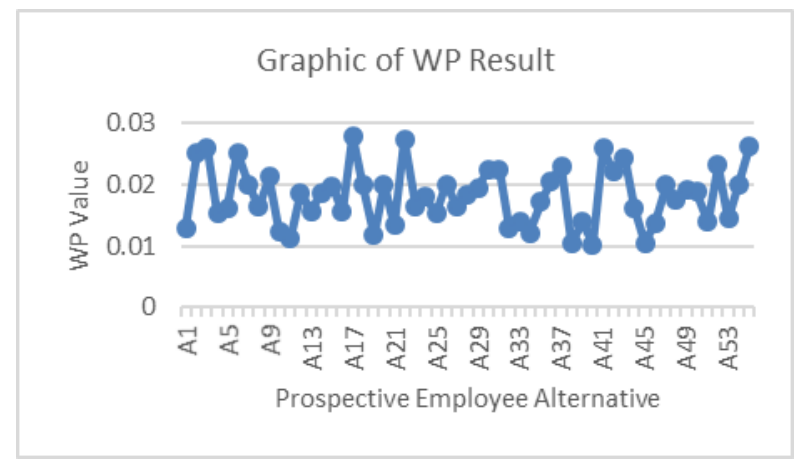

Figure 2. Graphic of The WP Calculation Method Results

Figure 1 and Figure 2 describe the results of the SAW and WP calculation method on any alternative candidate. From the figure can be concluded that there are some differences in rank calculation results from each method.

From the observations, the difference in alternatives rank order is influenced by several factors:

a. Performance rating value of alternative prospective employees factor

b. A weighting criteria factor

c. Calculation of each method factor

It is proven by the alternative of the same final preference value, but with the weight value criteria which make alternative with the best score and the greatest weight on the criteria takes precedence into a higher rank order than the alternatives that were also has the highest value, but on the lower criterion of weights value. Differences in the calculation basis of SAW and WP method also affect the different rank order of each method. SAW method which uses the addition as its basis made the results sequence are more fixated on the alternative with total value of final preference obtained from the highest rating value on the criteria with higher weight. While in WP methods, the obtained results order is influenced by multiplication operation as its calculation basis, so the order of the best results would be maximized if the alternative prospective employees do not have performance rating value equal to 1 , as in the operation of multiplication, any number if multiplied by 1 the result is the number itself and does not increase the value. So it can be said that the result of the WP calculation method is more detailed than the results given by the SAW method, since the WP method utilizing multiplication of the performance alternative rating value which is raised to the weight that has been improved. It is as revealed in the study [10] which states that SAW and WP methods calculation process is almost the same, what makes the difference is there is normalization process in the SAW method to resolve the variety of units ranges, while in the WP methods, the comparison of each alternative is done by multiplication of the ratio related to each criterion. That difference is what makes the final result of each method is also slightly different. 
In terms of execution time required for SAW and WP methods in the calculation process on Decision Support System, the execution time of each method are are shown in Figure 3.

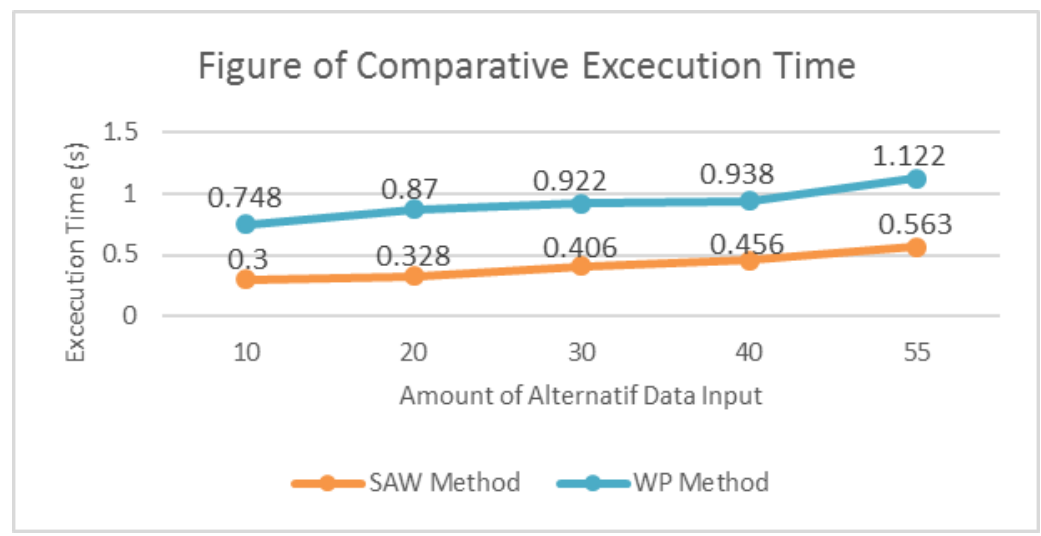

Figure 3. Comparison Graph of The Execution Time Results

From these images are ascertainable that the average of SAW method execution time is $0.4106 \mathrm{~s}$ while WP method execution time is $0.92 \mathrm{~s}$. The average of execution time is obtained by dividing the total execution time to the number of trials. From the average execution time is known that the SAW method is faster in performing the calculations on the New Employee Recruitment Decision Support System than the WP method. This is because the SAW method is using a simpler calculation method than WP method so that it taken less process. This is similar with research [11] which explains that with its calculation simplicity, made SAW method is the fastest method in the calculation process compared with any other MADM methods.

\section{CONCLUSION}

Based on the implementations of SAW and WP methods on the New Employee Recruitment DSS at PT. Warta Media Nusantara, ranking results is obtained in the form of 10 alternative ranking of top job candidates who accepted as new employees. The differences in the alternative rank ordering of SAW and WP methods are due to the influence of several factors: the alternative performance rating value, the criteria weight value, and the calculation of each method. WP method provides more thorough results than the SAW method. While in terms of execution time, SAW method requires shorter execution time than the WP method. That is because the SAW method has the simpler calculation process than the WP calculation method so that the execution time in SAW method on the New Employee Recruitment DSS faster than the execution time in WP method. 


\section{REFERENCES}

[1] Rivai, Veithzal. 2004. Manajemen Sumber Daya Manusia Untuk Perusahaan: Dari Teori Ke Praktik. PT. Raja Grafindo Persada, Jakarta.

[2] Kusumadewi, Sri., Hartati, S., Harjoko, A., and Wardoyo, R. 2006. Fuzzy MultiAttribute Decision Making (MADM). Yogyakarta: Graha Ilmu.

[3] Turban, E., Jay, E.A., \& Liang, T.P. 2005. Decision Support System and Intelligent System (Sistem Pendukung Keputusan dan Sistem Cerdas). Yogyakarta: Andi Offset.

[4] Poledníková, E., 2014. Multicriteria Evaluation Of Regional Disparities In Visegrad Four. In The 8th International Days of Statistics and Economics Conference Proceedings September 11-13, 2014, Prague, Czech Republic (pp. 1197-1207).

[5] Vyas Gayatri, S. and Misal Chetan S. 2013. Comparative Study of Different Multi-criteria Decision-Making Methods. International Journal on Advanced Computer Theory and Engineering (IJACTE), 2(4), 2319 - 2526.

[6] Deni, W., Sudana, O. dan Sasmita, A. 2013. Analysis and implementation fuzzy multi-attribute decision making SAW method for selection of high achieving students in faculty level. IJCSI International Journal of Computer Science Issues, 10(1), hal 65-85.

[7] Lestari, S. 2014. Penerapan Metode Weighted Product Model Untuk Seleksi Calon Karyawan. Jurnal Sistem Informasi, 5(1).

[8] Pressman, Roger S. 2001. Software Engineering: A Practitioner's Approach, 6th Edition. Singapore: McGraw-Hill, Inc.

[9] Kristanto, A. 2008. Perancangan Sistem Informasi dan Aplikasinya, Edisi Revisi. Yogyakarta: Gava Media.

[10] Kolios, A., Mytilinou, V., Lozano-Minguez, E. and Salonitis, K. 2016. A Comparative Study of Multiple-Criteria Decision-Making Methods under Stochastic Inputs. Energies, 9(7), p.566.

[11] Velasquez, M. and Hester, P.T. 2013. An Analysis of Multi-Criteria Decision Making Methods. International Journal of Operations Research, 10(2), pp.5666. 